\title{
Allowance Price Drivers in the First Phase of the EU ETS
}

Author: Beat Hintermann

Revised manuscript MS \# 18195

Date: July 31, 2009

Affiliation and contact information:

ETH Zurich

Centre for Energy Policy and Economics (CEPE)

Zuerichbergstr. 18, ZUE

8032 Zurich, Switzerland

Phone: +41-44-632-0652

Fax: $\quad+41-44-632-1622$

e-mail: bhintermann@ethz.ch 


\section{Abstract}

In the first phase of the EU Emissions Trading Scheme (EU ETS), the price per ton of CO2 initially rose to over $€ 30$; the price then collapsed to essentially zero by mid 2007. By deriving a structural model of the allowance price under the assumption of efficient markets I examine the extent to which this variation in price can be explained by marginal abatement costs. I then gradually relax the model by allowing for delayed adjustment of price to fundamentals, as well as by introducing lagged LHS variables. The pattern of the results suggests that while prices were not initially driven by marginal abatement costs, this inefficiency was largely corrected after the accounting of 2005 emissions in April 2006.

Keywords: Emissions permit markets, air pollution, climate change, bubble, speculation, $\mathrm{CO}_{2}$, asset pricing, EU ETS.

JEL classification: D84, G12, G14, Q52, Q53, Q54, Q58

Acknowledgements: I would like to thank Andreas Lange, John Horowitz, Marc Nerlove, Pete Kyle, Boraghan Aruoba, Charles Mason and two anonymous referees for valuable input. 


\section{Introduction}

The allowance price per ton of carbon dioxide $\left(\mathrm{CO}_{2}\right)$ in the first phase of the European Union Emissions Trading Scheme (EU ETS) caught many observers by surprise. It started at around $€ 5$ but quickly increased to a range of $€ 20-30$ where it remained for over a year. The price crashed after realized 2005 emissions were made public that showed the market to be over-allocated, but it recovered somewhat and remained at around $€ 15$ for another few months, before starting a gradual decline. By mid 2007, an allowance was virtually worthless.

Market analysts and economists alike have been looking for reasons behind the peculiar allowance price movement. Some have pointed to market fundamentals such as fuel prices and the weather [1, 2, 3, 4] but others have found no such correlation and confined themselves to forecasting based on pure time-series approaches [5, 6]. Whereas the April 2006 crash can be explained by the lower-than-expected overall emissions reports, it is not clear what drove the allowance price to those heights in the first place. Knowledge of aggregate emissions and abatement is not necessary for the efficiency of a permit market, since this information is supposed to be implicit in the market-clearing allowance price.

In this paper I examine if and to what extent the allowance price in the first phase of the EU ETS was based on market fundamentals related to aggregate abatement. I set up an economic model that specifies allowance price changes as a function of a set of widely accepted price drivers (fuel prices, temperature, reservoir levels, economic indicators and announcements of verified emissions), under the assumption of efficient markets and using the best data available. I then relax this model by introducing nonlinear terms, lagged fundamentals and lagged price changes and gauge their importance relative to the fundamentals. 
The results differ for the periods before and after the price adjustment. For the period after the crash, I find that a model in which fundamentals enter nonlinearly and that allows for gradual adjustment of the allowance price to fuel price changes is able to explain a large portion of the observed allowance price variation. In addition, many of the coefficients on the fundamentals are significant and have the expected sign. Introducing lagged allowance price changes improves the model only marginally, and the fundamentals retain their explanatory power.

For the pre-crash period, the model does not perform as well, even when allowing for nonlinear effects and gradual adjustment to fuel prices. Once introduced to the model, lagged price changes are the main price determinants, which may be a useful result for forecasting but certainly not for the identification of allowance price drivers. My results imply that the allowance price was not driven by marginal abatement cost determinants (with the possible exception of gas prices) before the first round of emissions accounting in April 2006, thus violating a necessary condition for a permit market to be an efficient policy instrument. Perhaps more importantly, they indicate that the market eventually corrected itself. However, the apparently inflated allowance price during the first 16 months of the market may have lead to over-abatement [7] and was passed through to output prices of the covered sectors $[8,9]$.

This paper makes two contributions: First, the stepwise procedure of starting with economic theory and then gradually introducing more flexibility allows insights into the determinants of the EU ETS allowance price that go beyond existing analyses. Second, I use a dataset of daily weather measurements in dozens of monitoring stations across Europe reaching back over three decades. No dataset of comparable quality has been used in the literature to address the influence of weather shocks on the allowance price. 


\section{The EU ETS}

The EU ETS is the world's largest emissions permit market to date and covers almost half of the EU's total $\mathrm{CO}_{2}$ emissions. The first phase of the market spanned the years 2005-2007 and was considered a pilot run for the second phase, which coincides with the Kyoto compliance period of 2008-2012. Pilot phase allowances (one-time rights to emit one ton of $\mathrm{CO}_{2}$ ) could not be banked into the second phase and lost their value if unused for compliance. The market applies to all EU countries, covers $\mathrm{CO}_{2}$ emissions from nine industry sectors defined by "activity code”" and allows for opt-ins from other sectors. In the first phase, about 11,000 individual installations received a total of 2,100 million emission allowances (EUAs) annually, mostly at no cost. For a more detailed discussion of the market setup, see [10] and [11].

Firms can trade allowances freely within the EU, either bilaterally, through brokers (over-thecounter or OTC trades) or on one of six exchanges. By April 30 of each year, they have to surrender permits corresponding to their emissions in the previous calendar year. This is also the date where each installation's realized and externally verified emissions from the previous calendar year are made public by each EU country. There is a penalty for noncompliance of $€ 40$ in phase 1 and $€ 100$ in phase 2 for every ton of emitted $\mathrm{CO}_{2}$ for which firms do not surrender an allowance; in addition, they have to surrender the missing allowances in the following year.

Because firms receive annual allowances in March of every year, they can effectively bank and borrow across time within phase 1. However, neither banking into nor borrowing from phase 2 is allowed, making phase 1 a self-contained market that is not related to future caps and political decisions regarding Kyoto. Banking from the second into later phases is permitted.

Allowance distribution and actual emissions by sector are shown in Figure 1 . Power \& heat received nearly $70 \%$ of the total allocation and is responsible for $72 \%$ of aggregate emissions 
covered by the market. ${ }^{2}$ This was the only sector with a net shortage of allowances, whereas all other sectors acted as net allowance suppliers. About $84 \%$ of the covered installations are relatively small with $<0.1$ million tons $(\mathrm{Mt})$ of $\mathrm{CO}_{2}$ emissions per year, and together they emit only about $8 \%$ of total emissions. At the other end of the spectrum, the top one percent of the installations together account for almost $40 \%$ of emissions. Most of these large emitters are power plants.

Figure 1: Allowance allocation and emissions by sector for 2006 (activity codes in parenthesis)

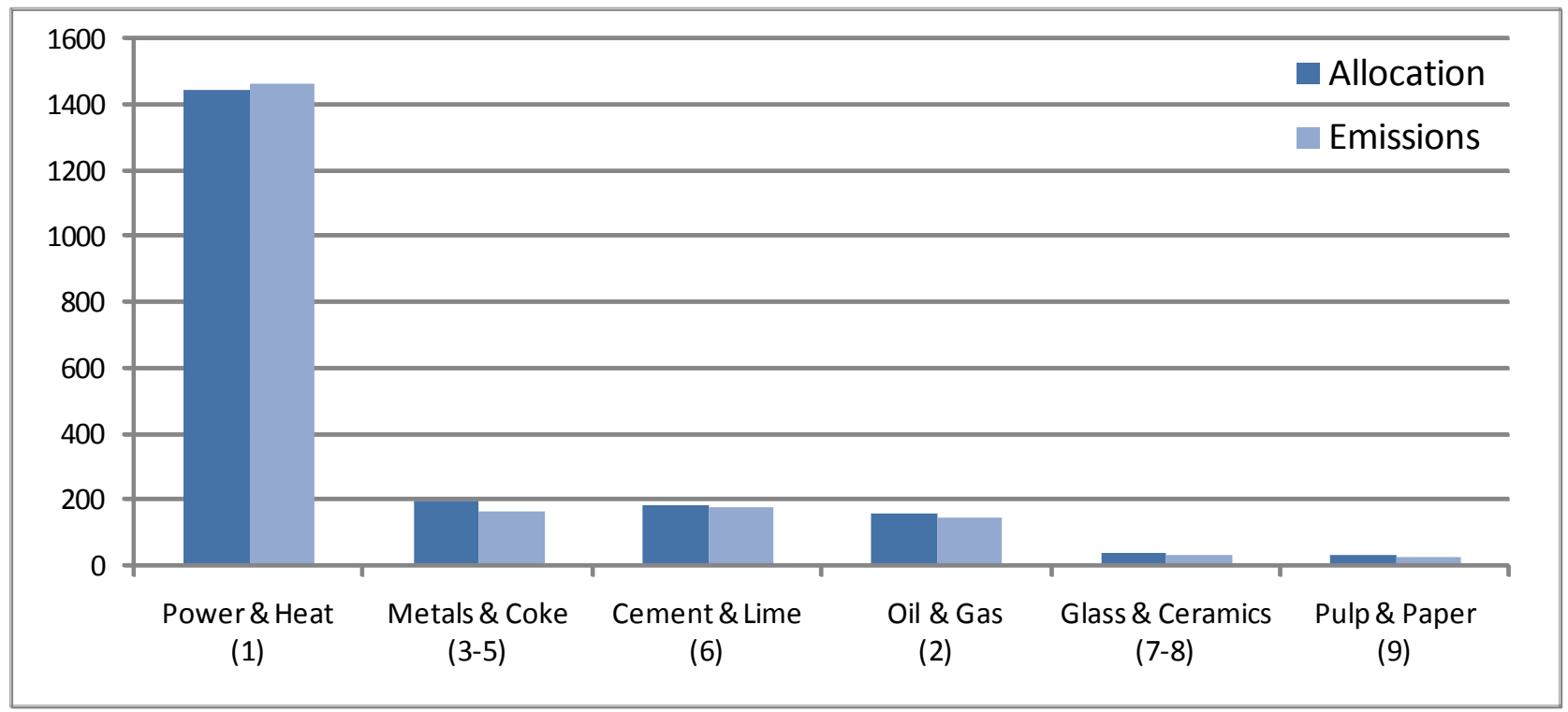

Allowance price realizations during the first phase of the EU ETS defied pre-market expectations. Because the emissions cap for the pilot phase was set rather generously, prices were generally predicted to be low. ${ }^{3}$ The actual daily allowance price and trading volumes are presented in Figure 2. The price increased from around €7 in January 2005 to above $€ 30$ in April 2006, before crashing to below $€ 10$ within three days. It then rose again and stabilized above $€ 15$ for about four months before decreasing to practically zero by mid 2007. The April price crash was triggered by the first round of emissions accounting (termed "emissions verification" in the EU 
ETS), which revealed that verified 2005 emissions were 94 Mt below the cap. ${ }^{4}$ The second round of emissions verifications in May 2007 again found the market to be long, but this no longer had a significant impact since prices had decreased to a few cents. Emissions verifications for 2007 occurred after the end of the phase 1. Liquidity was overall high, and a significant amount of the total allocation had been traded even in the first year. Table 1 shows a summary of the first phase.

Figure 2: EUA price and trading volumes

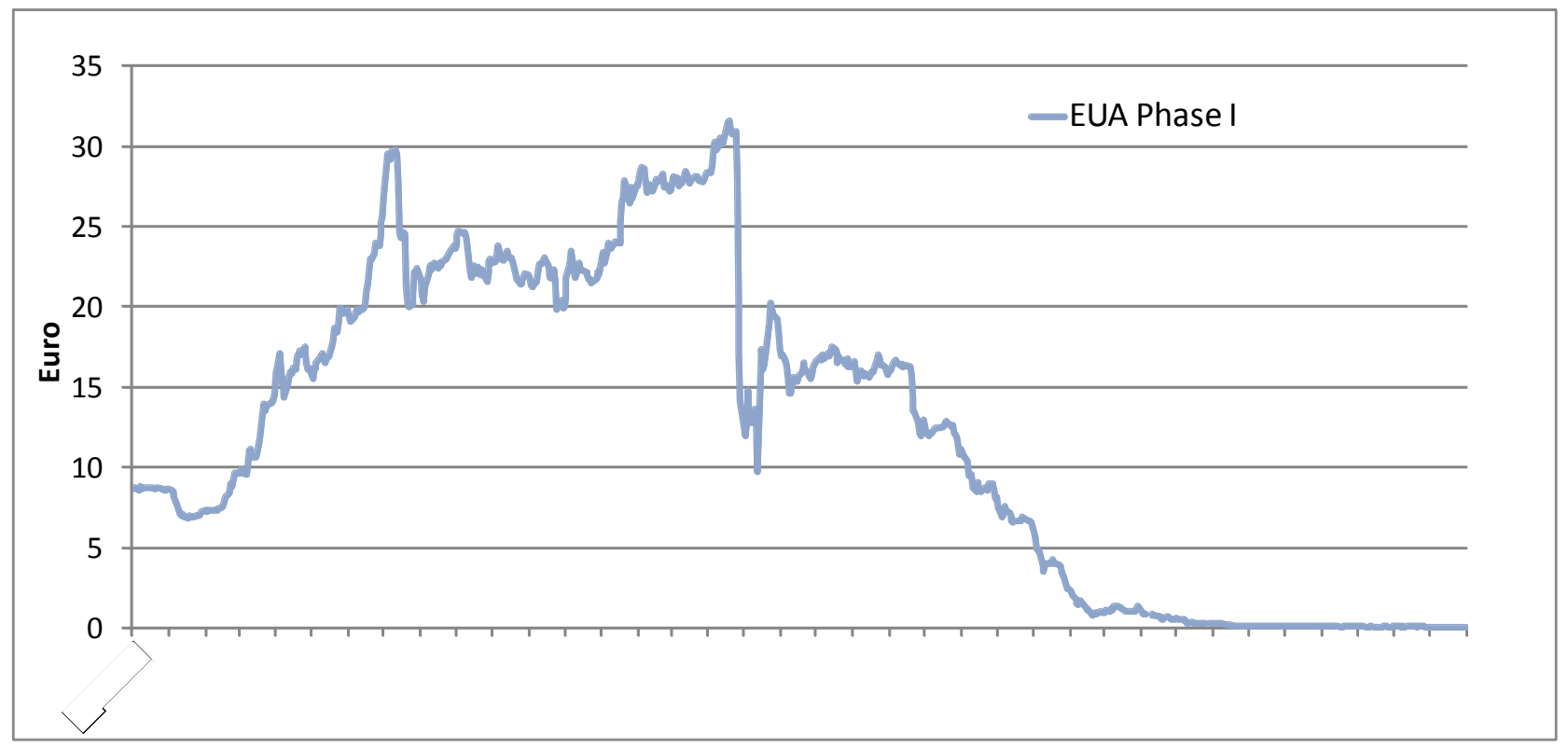

The fact that aggregate emissions in all three years were below the total allocation for those years is either due to over-abatement or over-allocation. Without the possibility of banking, abating more than necessary in the first period and using the freed-up allowances for compliance in later periods with a tighter cap is not an option. A preliminary analysis [7] implies that at least a part of the gap between emissions and allocation was due to abatement. The over-allocation was most likely not intentional but brought on by the fact that the EU did not have reliable information about firms’ actual emissions before the market started and largely defined allocations based on industry projections, with obvious incentive problems. 


\section{Allowance market model}

\subsection{Literature}

There is a large volume of empirical work on the $\mathrm{SO}_{2}$ permit trading system in the USA, e.g. $[13,14,15,16,17]$ and more recently $[18,19]$, to name only a few. For the EU ETS, the empirical literature is scarcer because it is a much newer market, and because fewer data are available in general since the involved firms previously faced little regulation. A number of studies model the EUA price and its volatility mainly for risk management and forecasting purposes [6, 20, 21, 22]. While useful for companies that need to hedge against the risk embedded in carbon prices, they do not shed much light on fundamental price drivers.

I am aware of four papers that explicitly aim to determine the impact of market fundamentals: Bunn and Fezzi [1] use a cointegrated VAR model with allowances, electricity and gas in the UK and daily temperature in London as an exogenous variable and impose the necessary identifying restrictions using auxiliary regressions. They find that the UK gas price influences the EUA price, and that both gas and EUA prices help determine the electricity price.

Mansanet-Batallet et al. [3] focused on EU-wide fuel prices and a weather index comprising several cities. They focus on the first year of the market only and include dummies for the six largest price changes, which end up accounting for most of the explanatory power of their model. This sidesteps the question of what actually drives the allowance price. In addition, they include regressors that are not obviously related to allowance prices, such as the oil price. ${ }^{5}$ They find that oil prices, natural gas prices and temperature in Germany are the only significant allowance price drivers, whereas other determinants turn out to be uncorrelated.

Alberola et al. [4] use temperatures in capital cities of six EU countries, along with a number of EU-wide energy variables, and extend the analysis to the first two years of the market. 
Unfortunately, they treat highly endogenous variables such as electricity prices, clean dark and clean spark spreads as exogenous determinants of the allowance price. This is no problem for forecasting, but endogeneity can lead to biased coefficient estimates of the price drivers.

Rickels et al. [2] build on [3], and include data through 2006. They separate allowance price determinants into supply and demand side and carefully choose the included market fundamentals. However, although they check for cointegration between allowance and fuel prices (they find none) and thus implicitly acknowledge the presence of unit roots in the price data, they specify their model in levels as opposed to differences (or returns) to render the data stationary. A nonstationary error is problematic because it may lead to biased coefficient estimates and results that are sensitive to the specific portion of the time series examined.

All four studies are valuable contributions to finding allowance price determinants, but in my view, none are based on a convincing market model. The inclusion/exclusion of market fundamentals as well as the econometric specification is mostly ad-hoc, which leads to the aforementioned problems. They also do not take into account the no-banking provision from the first into the second phase, and they include lagged EUA prices from the outset without discussing the economic meaning of this. In the following I set up a simple economic model of the allowance price and gradually extend it in order to address some of these issues.

\subsection{Base model}

In order to incorporate the uncertainty inherent in the demand and supply of allowances as well as the fixed time horizon of the first market phase, I extend a model proposed by Maeda [24]. Let the time index $=1, \ldots, \tau$ refer to days, where $\tau$ corresponds to the end of the first phase of the EU ETS. BAU ${ }_{\text {it }}$ denote firm i's random business-as-usual emissions (referring to emissions in the 
absence of a carbon cost) in period t, which are a function of a vector of normally distributed risk factors $\Psi$ shared by all $\mathrm{N}$ firms in the market:

$$
\begin{gathered}
B A U_{i t}\left(\Psi_{t}\right)=E_{t-1}\left[B A U_{i t}\left(\Psi_{t}\right)\right]+\beta_{i} *\left(\Psi_{t}-E_{t-1}\left[\Psi_{t}\right]\right)+\varepsilon_{i t} \\
\beta_{i}=\frac{\operatorname{Cov}\left(B A U_{i t}, \Psi_{t}\right)}{\operatorname{Var}\left(\Psi_{t}\right)} \\
E\left[\Psi_{t} \varepsilon_{i t}\right]=E\left[\varepsilon_{i t} \varepsilon_{j t}\right]=0, \quad i \neq j
\end{gathered}
$$

Firm i's BAU emissions in the current period are the sum of expected emissions and an adjustment term that is a function of shocks to $\Psi_{t}$ which contains exogenous variables that influence either demand or supply of emissions. Abatement is defined as the difference between firm i’s BAU emissions and actual emissions e:

$$
a_{i t}=B A U_{i t}\left(\Psi_{t}\right)-e_{i t}
$$

Abatement has a cost defined by a firm's abatement cost function or its derivative, the marginal abatement cost (MAC) function. Probably the best-known result in permit market theory is that each firm chooses a level of abatement such that its MAC is equal to the permit price in every period, which implicitly defines the optimal amount of abatement:

$$
\sigma_{t}=M A C_{i t}\left(a_{i t}^{*}, F_{t}, B A U_{i t}\left(\Psi_{t}\right)\right) \Rightarrow a_{i t}^{*}=M A C_{i t}^{-1}\left(\sigma_{t}, F_{t}, B A U_{i t}\left(\Psi_{t}\right)\right),
$$

where $F_{t}$ refers to a vector of variables that determines the MAC function. To clear the market, aggregate abatement has to equal the difference between aggregate BAU emissions and the emissions cap $S$ :

$$
\sum_{k=1}^{\tau} \sum_{i=1}^{N} a_{i k}^{*}=\sum_{k=1}^{\tau} \sum_{i=1}^{N} B A U_{i k}-S
$$


Because firms involved in the production of power and heat are dominant within the EU ETS, and because they may be able to abate emissions without either cutting output or building new plants (in contrast to the other sectors), I focus on emissions and abatement in this sector. I assume that the predominant method of abatement is a shift in the generation dispatch order ${ }^{6}$ away from hard coal towards gas, because the former is more than twice as emissions-intensive per unit of output than the latter. Fuel switching is generally considered to be abatement method of choice in the EU ETS [4, 22, 23, 25], given that there was not enough time between market setup and the end of the first phase for firms to alter production technology significantly. Because load factors for power generation are around 50\%, a production shift from coal to gas is more likely in this than in other sectors covered by the market. This means that in addition to BAU emissions, abatement costs in the EU ETS depend on gas and coal prices, which I will denominate with $G_{t}$ and $C_{t}$, and on capacity for production shifts.

Throughout this paper I assume that prices for gas and hard coal are exogenous to the allowance price. Although this is technically incorrect as these prices are simultaneously determined on international markets, I think that the introduced bias should be small for the following reasons: First, the EU satisfies $76 \%$ of its natural gas and $68 \%$ of its hard $\operatorname{coal}^{7}$ demand through imports, implying that European fuel markets are highly integrated into world markets. Second, demand by EU power \& heat producers amounts to $5.9 \%$ and $5.6 \%$ of world supplies of natural gas and hard coal, respectively, implying that a marginal change in demand due to the EU ETS should not have a large effect on the world price. ${ }^{8}$ Third, gas prices are indexed to the world oil price, which is unlikely to be significantly influenced by the EU ETS. And lastly, there appears to be no cointegration between fuel prices and the EUA price. 
If aggregate abatement costs are continuous and quadratic in abatement over the range where fuel switching is feasible, the market's abatement cost (AC) and marginal abatement cost (MAC) functions can be written as

$$
\begin{gathered}
A C_{t}\left(\sum_{i=1}^{N} a_{i t}, G_{t}, C_{t}\right)=b_{1 t} \sum_{i=1}^{N} a_{i t}+\frac{b_{2}}{2}\left(\sum_{i=1}^{N} a_{i t}\right)^{2} \\
b_{1 t} \equiv \lambda_{1} * G_{t}+\lambda_{2} * C_{t} \\
M A C_{t}\left(\sum_{i=1}^{N} a_{i t}, G_{t}, C_{t}\right)=b_{1 t}+b_{2} \sum_{i=1}^{N} a_{i t}
\end{gathered}
$$

The level of the MAC function is determined by coal and gas prices. Because initial marginal abatement costs are nonzero and fuel switching occurs from coal to gas, it must be that $b_{1 t}>0, \lambda_{1}>0$ and $\lambda_{2}<0$, whereas the slope $b_{2}>0$ ensures increasing marginal abatement costs. This parameter captures generator technology across the dispatch order and potentially other (but unidentified) reasons for an increasing aggregate MAC. ${ }^{9}$ In equilibrium, allowance demand must equal supply and the aggregate MAC has to equal the allowance price. This allows me to solve for the optimal aggregate abatement as a function of the allowance price:

$$
\sum_{i=1}^{N} a_{i t}=\frac{1}{b_{t}}\left(\sigma_{t}-b_{1 t}\right)
$$

Substituting (5) into (3) yields

$$
\frac{1}{b_{2}} \sum_{t=1}^{\tau}\left(\sigma_{t}-b_{1 t}\right)=\sum_{t=1}^{\tau} \sum_{i=1}^{N} B A U_{i t}-S
$$

I now take expectations at time t, subtract them from (6) and simplify:

$$
\sum_{k=t+1}^{\tau}\left(\sigma_{k}-E_{t}\left[\sigma_{k}\right]\right)=\sum_{k=t+1}^{\tau}\left(b_{1 k}-E_{t}\left[b_{1 k}\right]\right)+b_{2} * \sum_{k=t+1}^{\tau} \sum_{i=1}^{N}\left(B A U_{i k}-E_{t}\left[B A U_{i k}\right]\right)
$$


Entries for periods before t cancel out because their ex-post expectation is the same as their realization. Substituting (1) and dividing by N gives

$$
\frac{1}{N} \sum_{k=t+1}^{\tau}\left(\sigma_{k}-E_{t}\left[\sigma_{k}\right]\right)=\frac{1}{N} \sum_{k=t+1}^{\tau}\left(b_{1 k}-E_{t}\left[b_{1 k}\right]\right)+\frac{b_{2}}{N} \sum_{k=t+1}^{\tau} \sum_{i=1}^{N} \beta_{i} *\left(\Psi_{k}-E_{k-1}\left[\Psi_{k}\right]\right)+\frac{b_{2}}{N} \sum_{k=t+1}^{\tau} \sum_{i=1}^{N} \varepsilon_{i k}
$$

Provided that the error is stationary, the last term's mean and variance go to zero as $\mathrm{N}$ goes to infinity. The intuition behind this is that uncorrelated, firm-specific shocks cancel each other out in a large market, i.e. only shocks that affect all firms simultaneously have an impact on BAU emissions (and thus on marginal abatement costs). Setting $\bar{\beta}=1 / N * \sum_{i=1}^{N} \beta_{i}$, I can simplify to

$$
\sum_{k=t+1}^{\tau}\left(\sigma_{k}-E_{t}\left[\sigma_{k}\right]\right)=\sum_{k=t+1}^{\tau}\left(b_{1 k}-E_{t}\left[b_{1 k}\right]\right)+b_{2} N \bar{\beta} \sum_{k=t+1}^{\tau}\left(\Psi_{t}-E_{t-1}\left[\Psi_{t}\right]\right)
$$

If markets are efficient, prices incorporate changes in underlying fundamentals fully and immediately [26], implying that $E_{t}\left[P_{t+1}\right]=(1+r) P_{t} \equiv \rho P_{t}$, where $r$ is the interest rate and $P_{t}$ refers to any price. This only applies to prices, but not to stationary variables such as the weather. For this reason I will partition the vector $\Psi_{t}$ into stationary determinants collected in $\Psi_{t}^{S}$ and nonstationary determinants such as prices in $\Psi_{t}^{n}$. For $t<<\tau$, equation (7) can be solved recursively to ${ }^{10}$

$$
\sigma_{t}=\rho \sigma_{t-1}+b_{1 t}-\rho b_{1 t-1}+b_{2} N \bar{\beta}^{n}\left(\Psi_{t}^{n}-\rho \Psi_{t}^{n}\right)+b_{2} N \bar{\beta}^{S} \frac{\left(\Psi_{t}^{S}-E_{t-1}\left[\Psi_{t}^{S}\right]\right)}{\sum_{k=t}^{\tau} \rho^{\tau-k}}
$$

The allowance price is determined by the previous day's price, changes in fuel prices and shocks to $\Psi_{t}$. The summation term in the denominator of the RHS decreases through time and indicates that exogenous shocks to the stationary determinants of BAU emissions increasingly 
affect the permit price. Intuitively, such a shock should not influence the permit price much in the beginning of the market, as these determinants will return to their long-term mean and the shock is likely to be neutralized by a movement in the opposite direction later on. As time progresses, this “evening out” diminishes and individual shocks become more important. ${ }^{11}$ This does not apply to nonstationary determinants of BAU emissions, for which the summation term cancels out just like it does for permit and fuel prices.

The discount rate in equation (8) could be estimated directly using nonlinear tools. However, the day-to-day discount rate is close to zero. I therefore simplify to

$$
\Delta \sigma_{t}=\Delta b_{1 t}+b_{2} N \bar{\beta}^{n} \Delta \Psi_{t}^{n}+b_{2} N \bar{\beta} \frac{\left(\Psi_{t}^{S}-E_{t-1}\left[\Psi_{t}^{S}\right]\right)}{\sum_{k=t}^{\tau} \rho^{\tau-k}}
$$

where $\Delta$ refers to the first-difference operator. To keep the estimation linear I use an annual discount rate of $10 \%$ to calculate the denominator on the RHS. ${ }^{12}$

I assume that consumer demand is inelastic in the short term. Because demand must meet supply at all times in the electricity grid, $\Psi_{t}$ includes factors that determine either demand or supply of BAU emissions. In the base specification, I include temperatures across Europe, reservoir level changes in the Nordic countries and precipitation in non-Nordic countries ${ }^{13}$ in $\Psi_{t}^{S}$; and fuel prices and the FTSE Eurotop 100 (a tradable index representing the 100 most highly capitalized blue chip companies in Europe) in $\Psi_{t}^{n}$. The reasoning behind this choice is the following: Temperatures affect consumer demand through increased changes in heating (winter) or cooling (summer); reservoir levels and precipitation influence emissions on the supply side through the availability of renewable energy (assuming that all hydropower available is used because its marginal operating costs are below those of conventional generation [23]); fuel prices may 
determine emissions even in the absence of abatement through a change in the dispatch order; and the FTSE Eurotop 100 is a proxy for overall economic performance in the EU. I further introduce an $\mathrm{ARCH}(1)$ term in order to allow for a changing variance over time, which is standard procedure in the analysis of price series and a dummy indicating the first round of emissions verifications. This leads to the following specification:

$$
\begin{aligned}
\Delta \sigma_{t}= & \alpha_{1} \Delta G_{t}+\alpha_{2} \Delta C_{t}+\alpha_{3} \Delta F_{t}+\alpha_{4} D_{t} \\
& +\left(\alpha_{5} W_{t}+\alpha_{6} S_{t}\right) \frac{T_{t}-E\left[T_{t}\right]}{\sum_{k=t}^{\tau} \rho^{\tau-k}}+\alpha_{7} \frac{P_{t}-E\left[P_{t}\right]}{\sum_{k=t}^{\tau} \rho^{\tau-k}}+\alpha_{8} \frac{\Delta R_{t}-E\left[\Delta R_{t}\right]}{\sum_{k=t}^{\tau} \rho^{\tau-k}}+\varepsilon_{t} \\
& \varepsilon_{t} \sim N\left(0, \sigma_{t}^{2}\right) ; \quad \sigma_{t}^{2}=v_{0}+v_{1} \varepsilon_{t-1}^{2}
\end{aligned}
$$

$T_{t}$ and $P_{t}$ refer to weighted average daily temperature and precipitation (outside Nordic countries) in the EU, respectively; $R_{t}$ to Nordic reservoir levels; $F_{t}$ to the FTSE; $W_{t}\left(S_{t}\right)$ is a winter (summer) dummy taking the value of 1 in November through March (June through September), and zero otherwise; and $D_{t}$ is an emissions verification dummy equal to one on April 25-28, and zero otherwise. ${ }^{14}$ All other variables are as defined above, and $\alpha_{0}, \ldots, \alpha_{8}, v_{0}, v_{1}$ are parameters to be estimated.

In order to define shocks to reservoir levels and the weather, I need a measure of what their expected levels are. For reservoir levels $R_{t}$, I use weekly median levels $R_{t}^{\text {med }}$ based on the years 1991-2006. Because reservoir levels are a stock variable, I compute the flow by taking differences of both actual and median levels, such that $\Psi_{t}^{\text {Res }}-E\left[\Psi_{t}^{\text {Res }}\right]=\Delta R_{t}-E_{t-1}\left[\Delta R_{t}\right]=\Delta R_{t}-\Delta R_{t}^{\text {med }}$.

For temperature and precipitation, I construct daily expectations using 30-y means, i.e. $E_{t-1}\left[X_{t}\right]=1 / 30^{*} \sum_{y=1975}^{2004} X_{d y}$ for $X=T, P$, where $d$ refers to the calendar day corresponding to day $\mathrm{t}$ and $y$ to years. Because traders are likely to take weather forecasts into account and the 
weather over the weekends should influence Monday trades, I calculate 5-day moving averages of temperature and precipitation minus their expectation centered on the current day: $X_{t}-E_{t-1}\left[X_{t}\right]^{5 d} \equiv X_{t}^{5 d}=\sum_{k=t-2}^{t+2}\left(X_{k}-E\left[X_{k}\right]\right) / 5$

\section{Extensions}

\subsection{Introducing nonlinear terms}

I derived the base model using abatement costs that are linear in fuel prices and BAU determinants. This is a useful benchmark, but it may well be that some of the relationships are nonlinear. For example, increased rainfall may reduce BAU emissions quite strongly at first, but as the various reservoirs fill up, less of the additional precipitation can be captured, implying a diminishing marginal effect of rainfall on EU-wide BAU emissions. Temperature on the other hand may exhibit increasing marginal effects because heat loss is a square function of the difference between inside and outside temperatures. I will therefore introduce square terms of all variables.

Furthermore, it is possible that interaction effects exist. For example, an increase in BAU emissions (due either to a lack of rainfall or a cold spell in winter) coupled with an increase in gas prices may increase marginal abatement costs by more than the sum of the two isolated effects. Thus, I will include interaction terms between fuel prices and other BAU determinants. ${ }^{15}$

\subsection{Introducing dynamic expectations of fundamental prices}

Thus far I have assumed that EUA and fuel prices have the Markov property such that expectations about future prices are a function only of today's price but not of the preceding price path, and that spot and futures prices are equal except for a possible difference caused by storage 
costs [27]. The Markov property is the centerpiece of asset pricing for stocks and derivatives and implies that there are no arbitrage opportunities for chartist traders.

In reality, spot and futures prices can be quite different. Whatever the reason (asymmetric information, risk aversion, fixed contracts or bounded rationality), it is possible that traders form their expectations about prices for EUA fundamentals not only based on today’s prices, but also on past prices and/or a combination of spot and futures prices.

It is impossible to know a priori what prices and/or time lags best model traders’ expectations. I therefore estimate the model for a set of candidate specifications and choose the one with the best fit as measured by the sum of AIC and BIC. ${ }^{16}$ Specifically, I will combine up to three different gas prices $^{17}$ (spot, month-ahead and year-ahead futures) with appropriate square and interaction terms (for which I use only one gas price type per specification) and up to two price lags. Unfortunately, there are not several interchangeable measures for coal prices. The coal index for North-Western Europe (see data section below) seems by far the best available price information for hard coal. This procedure results in a total of 36 different candidate specifications. ${ }^{18}$

\subsection{Introducing lagged EUA price changes}

Although the variance in the base specification and Extensions 1 and 2 is allowed to vary over time due to the $\mathrm{ARCH}(1)$ term, the error itself is assumed to be uncorrelated over time. In order to reduce autocorrelation, most time series analyses include either lagged prices or AR terms in the error from the outset. There is no problem with this approach if the main goal is price forecasting, but what is the meaning of a lagged dependent variable in a structural equation that seeks to define price determinants? This question is routinely ignored, but in the current context this would be inappropriate. 
If the introduction of lagged dependent variables merely improves the model fit but does not qualitatively affect the explanatory power of the exogenous determinants (a change in the point estimates of the coefficients has to be expected with the introduction of a new significant variable into the model), then one can argue that they merely proxy for some form of inertia or an omitted variable that exhibits autocorrelation. However, if they take over as the major source of explanatory power, then this indicates that something in the model is amiss.

\section{Results}

\subsection{Data}

For my regressions and tests I use the following data:

EUA prices: Daily series of over-the-counter (OTC) prices, Point Carbon. ${ }^{19}$

Gas prices: ICE month-ahead futures and Zeebrugge day-ahead prices for UK natural gas (“spot”), and TTF year-ahead contracts for natural gas in continental Europe.

Coal prices: McCloskey coal marker for North-Western Europe, which incorporates information on all trades involving hard coal that enters Europe from abroad within the next three months. It is an average of actual transactions or, in their absence, an assessment of fair value by traders. This marker is published weekly and generally viewed as the most comprehensive available price information for hard coal.

Temperature and precipitation: From the European Climate Assessment \& Dataset ${ }^{20}$, which contains daily entries from a large number of monitoring locations across Europe. I weighted temperature deviations by population around each monitoring location and precipitation by installed hydroelectric capacity. 


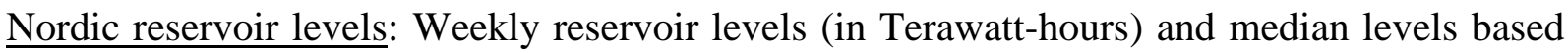
on 1991-2006 taken from the Nordpool exchange. The Nordpool market (composed of Norway, Sweden, Denmark and Finland) is an important hydropower-producing region in Europe.

\subsection{Estimation results}

Visual inspection of the price graph as well as previous analyses [1, 4] indicate that the relationship between market fundamentals and the allowance price likely changed after the first emissions verification. I therefore estimate equation (10) separately for the time between January 2005 and June 2007 (“full period”; in July 2007, prices decreased to practically zero and remained at that level until the end of the market, which makes an inclusion of the last six months pointless), as well as for the period before the price crash induced by the first round of emissions verifications in April 2006 (“pre-crash”) and after (“post-crash”).

Table 2 presents the results from the base regression. Gas prices are positive and significant for all periods, and precipitation is significant in the post-crash period. The crash dummy and the ARCH term are highly significant, but none of the other variables is correlated with EUA price changes. Because the FTSE is not significant in any specification and its presence (including the square and interaction terms) leads to multicollinearity in the extension specifications, I reestimated all models without it. ${ }^{21}$

Along with the AIC and BIC I also compute the Cox-Snell generalized $\mathrm{R}^{2}$ as a more intuitive measure of model fit, defined by $R^{2}=1-[L(0) / L(\hat{\theta})]^{2 / n}$, where $L(\hat{\theta})$ and $L(0)$ refer to the likelihood of the full model and of a model that contains only an intercept and an ARCH(1) term, respectively, and $\mathrm{n}$ is the number of observations. The generalized $\mathrm{R}^{2}$ can be interpreted as the percentage of the variation of the dependent variable explained by the model, relative to the variation left unexplained by the null model [28]. The full model including the verification dummy 
accounts for about $15 \%$ of this variation, whereas for the pre- and post-crash periods, the model explains $6 \%$ and $17 \%$, respectively. The standardized residuals defined by $\varepsilon_{t}^{*}=\varepsilon_{t} / \sigma_{t}$ exhibit strong serial correlation in all periods, as evidenced by the Ljung-Box $Q(k)$ statistic, with the number of lags $\mathrm{k}$ chosen as the largest integer for which $k \leq[2 \sqrt{N}]$.

The coefficient estimates are significantly different before and after the price crash based on an LR test, confirming the suspected structural break. I therefore restrict estimation of the remaining regressions to the two sub-periods. The first panel of Table 3 contains the results from extension 4.1. The introduction of the 14 nonlinear terms leads to an increase in the $\mathrm{R}^{2}$ by construction, as the model likelihood is nondecreasing in the number of included regressors. Also, the coefficients on Nordic reservoir levels, their squares, and their interaction with coal prices are significant and have the expected sign. However, the increase of both AIC and BIC for the precrash model relative to the base specification implies that the model did not qualitatively improve by including these extra terms, and serial correlation of the standardized residuals persists. This is confirmed by a likelihood ratio test of extension 4.1 against the (nested) base model, which reveals that the added terms are jointly insignificant. In contrast, both AIC and BIC decrease for the postcrash period, the LR test is highly significant, and the standardized residuals are not serially correlated, indicating a clear improvement due to the introduction of the nonlinear terms. For this period, the extended model explains $48 \%$ of the variation in price changes that is not accounted for by the ARCH(1) null model, and many of the additional explanatory variables are significant and have the correct sign.

Results from the "winners" of the 36 candidate specifications for extension 4.2 are shown in the central panel of Table 3. For the pre-crash period, a specification including twice-lagged month-ahead and year-ahead futures (with squares and interaction terms computed with the latter) 
exhibits the best model fit and decreased serial correlation. The LR test indicates that the additional terms (relative to extension 1) are jointly significant. The AIC is now smaller than in the base specification, but the BIC is still higher (note that the AIC does not punish parsimony as much as the BIC, and extension 4.2 contains 23 more parameters than the base specification). The coefficients related to Nordic reservoir levels are still significant, as well as three of the gas price coefficients (two positive, one negative).

In contrast, the model fit improves significantly and unambiguously for the post-crash period, where the best specification involves the use of spot, month-ahead, and year-ahead gas prices and two price lags (interaction terms computed with year-ahead futures). The model now accounts for $60 \%$ of the price change variation unaccounted for by the null model. Both AIC and BIC have further improved (i.e. decreased) relative to the base specification and extension 4.1, and the standardized residuals are not serially correlated. The interpretation of the individual coefficients on gas prices in the simultaneous presence of three different gas price "flavors" and two time lags is not straightforward, but in aggregate an increase in gas (coal) prices increases (decreases) the allowance price as expected. Most of the other determinants are meaningfully and significantly associated with EUA prices, and both precipitation and Nordic reservoir level exhibit negative and diminishing effects consistent with the underlying theory.

The rightmost panel in Table 3 presents the results from extension 4.3. Introducing three lags of allowance price changes is effective in explaining current price changes in the pre-crash period as evidenced by the decreased BIC and AIC, increased $\mathrm{R}^{2}$ and significant LR test, and in removing serial correlation. However, most of the coefficients on the fundamentals remain insignificant, indicating that the true price drivers have not been identified. After the crash, introducing one lagged dependent variable decreases both AIC and BIC and further improves the explanatory power of the model, although the increase of the $\mathrm{R}^{2}$ is rather small. Most of the exogenous 
determinants related to EUA prices in extension 4.2 remain significant, with the exception of coal prices and summer temperatures.

\section{Discussion}

Taken together, the results shown in Tables 2-3 imply the following:

a.) There was a structural break in allowance price determination after the price adjustment due to the emissions verifications in April 2006. Whereas the market fundamentals identified in this paper explain a significant portion of the variation in EUA price changes in the post-crash period, this is not the case before the price crash except for gas prices and Nordic reservoir levels.

b.) Coefficients on fuel prices, temperature and availability of hydroelectric power are statistically significant and have the expected sign for the period after the price adjustment. This is consistent with results obtained by [1] and [4].

c.) In the post-crash period, market fundamentals drive the allowance price in a nonlinear way. The introduction of squared and interaction terms significantly improves the model. This is not the case before the crash.

d.) Allowance prices appear to violate the Markov property. Market fundamentals are not immediately internalized, as a combination of spot and futures prices and lagged prices significantly improve the model (extensions 4.2 versus 4.1). This could be due to some form of market learning on behalf of market participants and implies that arbitrage opportunities existed.

e.) Introduction of lagged EUA price changes only marginally improves the model for the post-crash period, but significantly so before the crash. Although gas prices and Nordic reservoir

levels contribute to the explanatory power in extension 4.3, the most important “determinants” of EUA price changes are lagged price changes. 
I chose the market fundamentals in this analysis based on the premise of equality between allowance price and marginal abatement costs. Assuming that my market model is correct and that I did not exclude a crucial price driver that is linked to aggregate abatement and exhibits severe autocorrelation, my results imply that marginal abatement costs were most likely not equal to the permit price during the first 16 months of the market. Since this equality is a necessary condition for a permit market to achieve a given emissions reduction at least cost, the market was not efficient during that period. After the first round of emissions verifications, the market appears to have largely corrected itself in the sense that the EUA price reacted more consistently to fundamentals.

Because of the eventual correction, the question as to what caused the allowance price to deviate from marginal abatement costs may be moot for the EU ETS itself. However, the price stayed too high for a long period and was passed on to consumers, with likely negative effects on overall welfare and firms' abatement choices. It is therefore in the interest of future markets to avoid a similar situation.

In order to identify policy recommendations that would allow future markets to attain efficiency faster than the EU ETS, it is necessary to know the reason why the allowance price was initially not determined by marginal abatement costs. In the next subsection I propose four different (but not mutually exclusive) hypotheses, along with a selection of policy instruments that could be used to address them.

\section{$6.1 \mathrm{~A} \mathrm{CO}_{2}$ Bubble?}

In a bubble, the price is disconnected from fundamentals and driven by self-fulfilling expectations, which would be consistent with the above results. In a discrete-time setting with 
fully informed and rational agents, a bubble cannot exist on theoretical grounds [29, 30], but introduction of continuous time (thus neutralizing the backward induction argument) or allowing for incomplete information and/or some sort of bounded rationality on behalf of traders renders a bubble possible [31, 32, 33]. Bubbles and "herding" behavior have been shown to exist and persist in experiments even with experienced subjects [34, 35].

Anything that temporarily increases the price above its fundamental value could lead to selffulfilling expectations of further increases. In the EU ETS, this initial price increase could have been caused by an (overly) bullish market report, price manipulation by dominant market players or any fundamental-based price increase that was not recognized as such by some traders who then expected future increases even when the underlying reason for the price increase vanished.

Unfortunately, it is impossible to conclusively prove the existence of a bubble, because there is always an alternate hypothesis of a misspecified market model [36]. Gurkaynak [37] provides a survey of bubble tests, among which cointegration and regime-switching tests appear to be most promising in the permit market context. Cointegration tests are based on the assertion that in an exponentially growing bubble, a cointegrating vector cannot exist that renders a linear combination of integrated dependent and independent variables stationary, as this would in effect prove a systematic relationship between price and fundamentals [30, 38, 39]. I tested for cointegration between EUA prices, fuel prices, Nordic reservoir levels and the FTSE (all of which are integrated of order 1 based on unit root tests) and found none. This is consistent with the presence of a bubble, but of course lack of cointegration could also be caused by other reasons.

Regime-switching bubble tests rely on the premise that price changes are governed by different distributions in a bubble's boom and bust phases, and that the state in one period is influenced by last period's state. Such tests in principle allow for detection of stochastically crashing bubbles that are difficult to detect otherwise [40, 41, 42, 43]. I carried out a regime- 
switching test as outlined by [44] and proxied the bubble term with lagged allowance price levels. The bubble test consists of testing whether a) the coefficients of the bubble term are as expected (i.e. positive during boom and negative during bust), and b) the state probability depends on the state in the previous period. In both cases I was not able to reject the null hypothesis of no bubble in the pre-crash period, but the power of the test may be weak. ${ }^{22}$

Strategies to avoid bubbles in future markets include more frequent emission verifications, especially in the beginning of the market, and the possibility of short selling of allowances. To the extent that they improve information about marginal abatement costs, permit auctions could also reduce the potential for a speculative permit price bubble.

\subsection{Market power}

It is possible that the allowance price was not set by the interaction of price takers in an efficient market, but that dominant players set the price so as to maximize their own profits. This could decouple the allowance price from the fundamentals considered here if dominant firms' ability to influence the price changes over time. Of all market participants in the EU ETS, large power producers exhibit the greatest potential for market power, and, as it happens, they also reaped large profits from the initially high EUA price due to a combination of free allocation and cost pass-through [8, 9, 45, 46, 47]. Power and heat producers were net demanders of allowances and therefore Hahn's [48] prescription about market power in permit markets indicates that they would have used any market power to depress the price rather than inflate it. However, [49] proves that when taking the interaction between output and permit market into account, even net permit demanders can find it profitable to inflate the permit price, provided that their free allowance allocation exceeds a specific threshold that is a function of cost throughput and firms' relative emission intensities. Market data from the UK and Germany indicate that power producers 
indeed received an allocation in excess of this threshold. Whether firms in the EU ETS actually exerted market power is a question that cannot be answered before trading data are made available, which is five years after the fact. An obvious solution to fix or alleviate price inflation due to market power is to reduce the amount of free allocation to firms, although full efficiency cannot be achieved by means of allocation alone.

\subsection{Firms hedging against stochastic emissions}

If firms were unable to effectively control their emissions in time for phase 1, either because abatement was simply not feasible in the short-run because firms were locked into long-term contracts, or because emissions are a function of stochastic output, then firms have to hedge against the probability of having to pay a penalty. Each additional allowance relieves them from the obligation to pay a penalty if the cap turns out to be binding, but becomes an unnecessary expense otherwise. This means that at the end of the market, an allowance is either worth the

penalty for noncompliance or zero. If firms view emissions as stochastic, the allowance price is not related to any form of abatement costs but to the discounted penalty of noncompliance multiplied by the probability of a binding cap [6]. [50] develops and estimates such a model and finds that it fits the data quite well. There is little that can be done to counter firms' inability to control emissions, other than possibly increasing the period between legal inception and the start of the market.

\subsection{Allocation updating}

Although EU member countries based free allocation for phase 1 on historic emissions and/or projections and the European Commission strongly suggested that only historic emissions be used when deciding on allocations for later phases, most EU countries based their National Allocation Plans for phase 2 on verified emissions from 2005. Such allocation "updating” results in a 
disincentive to abate, and $[51,52]$ formally show that the permit price will be greater in this case than if allocations were fixed based on historic emissions.

If allocation rules were the same in all countries, allocation updating would simply lead to a (constant) wedge between marginal abatement costs and the allowance price. But because each EU member state defines its own allocation rules, the "penalty" for abating in the form of a decreased future free allocation differs across countries, possibly canceling the effect of the fundamentals. However, empirically testing whether allocation updating was partly responsible for the apparent deviation between marginal abatement costs and allowance price in the beginning of the market would require knowledge of abatement cost functions by country, which is not readily available. Allocation updating can and should be avoided (either by one-off grandfathering or auctioning) because it is clearly not incentive-compatible.

\section{Conclusions}

In the first phase of the EU ETS, the allowance price exhibited high volatility and followed a peculiar path. The crash in April 2006 was most likely caused by an adjustment of expectations about aggregate emissions, but it is not obvious what drove the price that high in the first place. In

this paper I examine if and to what extent the allowance price was determined by market fundamentals related to aggregate marginal abatement costs.

I derive a market model that expresses allowance price changes as a function of fuel prices, temperatures, the availability of hydroelectric power and stock market indices, and find that it fits the data reasonably well after the first round of emissions verifications, but not before. The most important allowance price determinants after the crash are fuel prices, summer temperatures and precipitation, which appear to influence the allowance price in a nonlinear way. There is some 
evidence that the allowance price did not immediately incorporate new market information, which may be a sign of learning on behalf of traders in a new market.

The model does not work nearly so well for the period before the first round of emissions verifications, and the variables that explain the overwhelming part of the pre-crash price variation are lagged allowance price changes.

Equality of allowance price and marginal abatement costs is a necessary condition for every permit market to achieve its main goal, which is to attain a given emissions reduction at least cost. My results imply that this equality most likely did not hold before the price crash and that therefore the market was initially inefficient. This is the main finding of this paper. One could argue that the crucial thing is that the market eventually corrected itself, but it is important to note that the correction did not take place until 16 months after the start, and that during this time the apparently inflated allowance price was passed on to consumers via higher electricity and other prices.

In order for future markets to avoid the same start-up problems, it is necessary to identify the true allowance price drivers in the beginning of the market. Although a conclusive answer to this question exceeds the scope of this paper, I propose four alternative explanations: 1) An allowance price bubble, 2) market power on behalf of power and heat companies, 3) firms hedging against stochastic emissions and 4) allocation "updating” by EU countries when defining National Allocation Plans for phase 2. All four explanations are possible on theoretical grounds and consistent with initial price inflation, and there is some empirical evidence for (potential) price manipulation and emissions hedging by firms, whereas the evidence for a $\mathrm{CO}_{2}$ bubble is inconclusive. More research is needed to identify the root of the initial market inefficiency in order to prevent future markets from suffering the same experience. 


\section{References}

[1] D.W. Bunn, and C. Fezzi, A vector error correction model of the interactions among gas, electricity and carbon prices: An application to the cases of Germany and United Kingdom. in: F. Gulli, (Ed.), Markets for carbon and power pricing in Europe: Theoretical issues and empirical analyses, Edward Elgar Publishing, 2008, pp. 145-159.

[2] W. Rickels, V. Dusch, A. Keller, and S. Peterson, The determinants of allowance prices in the European Emissions Trading Scheme - Can we expect an efficient allowance market 2008? , Kiel Institute for the World Economy Working Paper No. 1387, 2007, pp. 28.

[3] M. Mansanet-Bataller, A. Pardo, and E. Valor, CO2 Prices, Energy and Weather. The Energy Journal 28 (2007) 73-92.

[4] E. Alberola, J. Chevallier, and B. Cheze, Price drivers and structural breaks in European carbon prices 2005-2007. Energy Policy 36 (2008) 787-797.

[5] M.S. Paolella, and L. Taschini, An Econometric Analysis of Emission Trading Allowances, Research Paper Series, Swiss Finance Institute, Zurich, 2006, pp. 45.

[6] M. Chesney, and L. Taschini, The Endogenous Price Dynamics of the Emission Allowances: An Application to CO2 Option Pricing, Swiss Finance Institute Research Paper Nr. 08-02, Zurich, 2008.

[7] A.D. Ellerman, and B. Buchner, Over-allocation or abatement? A preliminary analysis of the EU ETS based on the emissions 2005 data. Environmental and Resource Economics 41 (2008) 267-287.

[8] R. Smale, M. Hartley, C. Hepburn, J. Ward, and M. Grubb, The impact of CO2 emissions trading on firm profits and market prices. Climate Policy 6 (2006) 29-46. 
[9] J. Sijm, K. Neuhoff, and Y. Chen, CO2 cost pass through and windfall profits in the power sector. Climate Policy 6 (2006) 49-72.

[10] J. Kruger, and W. Pizer, The EU Emissions Trading Directive: Opportunities and Potential Pitfalls, Resources for the Future discussion papers, Washington, D.C., 2004, pp. 62.

[11] PEW Center on Global Climate Change, The European Emissions Trading Scheme (EUETS); Insights and Opportunities, 2005, pp. 20.

[12] J.M. Reilly, and S. Paltsev, An Analysis of the European Emission Trading Scheme, Joint Program on the Science \& Policy of Global Change, Massachussetts Institute of Technology, Cambridge, MA, 2005, pp. 27.

[13] P.L. Joskow, R. Schmalensee, and E.M. Bailey, The Market for Sulfur Dioxide Emissions. American Economic Review 88 (1998) 669-85.

[14] R. Schmalensee, An Interim Evaluation of Sulfur Dioxide Emissions Trading. Journal of Economic Perspectives 12 (1998) 53-68.

[15] R.N. Stavins, What Can We Learn from the Grand Policy Experiment? Lessons from SO2 Allowance Trading. Journal of Economic Perspectives 12 (1998) 69-88.

[16] C. Carlson, Sulfur Dioxide Control by Electric Utilities: What Are the Gains from Trade? Journal of Political Economy 108 (2000) 1292-1326.

[17] J.-P. Montero, Voluntary Compliance with Market-Based Environmental Policy: Evidence from the U S Acid Rain Program. Journal of Political Economy 107 (1999) 998-1033.

[18] D. Burtraw, K. Palmer, M.L. Cropper, and C. Carlson, Sulfur-Dioxide Control By Electric Utilities: What are the Gains from Trade? , Resources for the Future, Washington, DC, 2005, pp. 34. 
[19] R.F. Kosobud, H.H. Stokes, C.D. Tallarico, and B.L. Scott, Valuing Tradable Private Rights to Pollute the Public's Air. Review of Accounting and Finance 4 (2005) 50-71.

[20] E. Benz, and S. Trück, Modeling the price dynamics of CO2 emission allowances. Energy Economics 31 (2009) 4-15.

[21] J. Seifert, M. Uhrig-Homburg, and M. Wagner, Dynamic Behavior of CO2 Spot Prices. Journal of Environmental Economics and Management 56 (2008) 180-194.

[22] M. Fehr, and J. Hinz, A quantitative approach to carbon price risk modeling, Working paper, ETH Zurich, 2006.

[23] A.C. Christiansen, A. Arvanitakis, and H. Hasselknippe, Price Determinants in the EU Emissions Trading Scheme. Climate Policy 5 (2005) 15-30.

[24] A. Maeda, Impact of Banking and Forward Contracts on Tradable Permit Markets. Environmental Economics and Policy Studies 6 (2004) 81-102.

[25] E.D. Delarue, and W.D. D'haeseleer, Price determination of ETS allowances through the switching level of coal and gas in the power sector. International Journal of Energy Research 31 (2007) 1001-1015.

[26] B.G. Malkiel, A random walk down Wall Street: The time-tested strategy for successful investing,, W. W. Norton \& Company,, New York, 2007.

[27] J.C. Hull, Options, Futures, and Other Derivatives, Ch. 11,, Prentice Hall,, Upper Saddle River, NJ, 2002.

[28] N.J.D. Nagelkerke, A note on a general definition of the coefficient of determination. Biometrika 78 (1991) 691-692. 
[29] J. Tirole, On the Possibility of Speculation under Rational Expectations. Econometrica 50 (1982) 1163-81.

[30] B.T. Diba, and H.I. Grossman, On the Inception of Rational Bubbles. Quarterly Journal of Economics 102 (1987) 697-700.

[31] J.A. Frankel, and K.A. Froot, Chartists, Fundamentalists, and Trading in the Foreign Exchange Market. American Economic Review 80 (1990) 181-85.

[32] D. Friedman, and M. Aoki, Inefficient Information Aggregation as a Source of Asset Price Bubbles. Bulletin of Economic Research 44 (1992) 251-79.

[33] C. Camerer, Bubbles and Fads in Asset Prices. Journal of Economic Surveys 3 (1989) 3-41.

[34] M. Cipriani, and A. Guarino, Herd Behavior in Financial Markets: An Experiment with Financial Market Professionals. Journal of the European Economic Association 7 (2009) 206-233.

[35] R.N. Hussam, D. Porter, and V. Smith, Thar She Blows: Can Bubbles Be Rekindled with Experienced Subjects? American Economic Review 98 (2008) 924-937.

[36] R.P. Flood, and P.M. Garber, Market Fundamentals versus Price-Level Bubbles: The First Tests. Journal of Political Economy 88 (1980) 745-70.

[37] R.S. Gurkaynak, Econometric tests of asset price bubbles: taking stock, Federal Reserve Board, Division of Research \& Statistics and Monetary Affairs, Washington, DC, 2005, pp. 34.

[38] B.T. Diba, and H.I. Grossman, The Theory of Rational Bubbles in Stock Prices. Economic Journal 98 (1988) 746-54. 
[39] J.D. Hamilton, and C.H. Whiteman, The Observable Implications of Self-fulfilling Expectations. Journal of Monetary Economics 16 (1985) 353-73.

[40] C. Engel, and J.D. Hamilton, Long Swings in the Dollar: Are They in the Data and Do Markets Know It? American Economic Review 80 (1990) 689-713.

[41] S.G. Hall, Z. Psaradakis, and M. Sola, Detecting Periodically Collapsing Bubbles: A Markov-Switching Unit Root Test. Journal of Applied Econometrics 14 (1999) 143-54.

[42] H. Schaller, and S. van Norden, Regime Switching in Stock Market Returns. Applied Financial Economics 7 (1997) 177-91.

[43] C.-J. Kim, J. Piger, and R. Startz, Estimation of Markov regime-switching regression models with endogenous switching. Journal of Econometrics 143 (2008) 263-273.

[44] J.D. Hamilton, A New Approach to the Economic Analysis of Nonstationary Time Series and the Business Cycle. Econometrica 57 (1989) 357-84.

[45] M. Grubb, and K. Neuhoff, Allocation and competitiveness in the EU emissions trading scheme: Policy overview. Climate Policy 6 (2006) 7-30.

[46] C. Hepburn, M. Grubb, K. Neuhoff, F. Matthes, and M. Tse, Auctioning of EU ETS Phase II allowances: How and why? Climate Policy 6 (2006) 137-160.

[47] K. Neuhoff, K. Keats, and M. Sato, Allocation, incentives and distortions: the impact of EU ETS emissions allowance allocations to the electricity sector. Climate Policy 6 (2006) 7391.

[48] R.W. Hahn, Market Power and Transferable Property Rights. Quarterly Journal of Economics 99 (1984) 753-65. 
[49] B. Hintermann, Market Power and Windfall Profits in Emission Permit Markets, CEPE working paper \# 62, ETHZ, Zurich, 2009.

[50] B. Hintermann, An Options Pricing Approach to CO2 Allowances in the EU ETS, CEPE working paper \# 64, ETHZ, Zurich, 2009.

[51] C. Boehringer, and A. Lange, On the Design of Optimal Grandfathering Schemes for Emission Allowances. European Economic Review 49 (2005) 2041-55.

[52] T. Sterner, and A. Muller, Output and Abatement Effects of Allocation Readjustments in Permit Trade, RFF Discussion Paper DP 06-49, RFF, Washington, D.C., 2006, pp. 29. 


\section{Tables}

Table 1: Summary results for Phase I of the EU ETS

\begin{tabular}{lllll}
\hline & 2005 & 2006 & 2007 & Total Phase I \\
\hline Price (time average) & $€ 18.40$ & $€ 18.05$ & $€ 0.72$ & $€ 12.39$ \\
Trading volume $^{\mathrm{a}}$ & $262 \mathrm{Mt}$ & $817 \mathrm{Mt}$ & $1,364 \mathrm{Mt}$ & $2,443 \mathrm{Mt}$ \\
Trading value $^{\mathrm{a}}$ & $€ 5.4 \mathrm{billion}$ & $€ 14.6 \mathrm{billion}$ & $€ 28.0 \mathrm{billion}$ & $€ 48.0 \mathrm{billion}$ \\
Allocation & $2,099 \mathrm{Mt}$ & $2,072 \mathrm{Mt}$ & $2,079 \mathrm{Mt}$ & $6,250 \mathrm{Mt}$ \\
Emissions & $2,010 \mathrm{Mt}$ & $2,031 \mathrm{Mt}$ & $2,041 \mathrm{Mt}$ & $6,081 \mathrm{Mt}$ \\
Surplus (volume) & $89 \mathrm{Mt}$ & $41 \mathrm{Mt}$ & $39 \mathrm{Mt}$ & $168 \mathrm{Mt}$ \\
Surplus (\%) & $4.22 \%$ & $1.98 \%$ & $1.85 \%$ & $2.69 \%$ \\
\hline
\end{tabular}

a: Based on OTC and exchange trading for Phase I and II, but excluding bilateral trades

Table 2: Results from base estimation (Equation 10); dependent variable: Daily EUA price changes

\begin{tabular}{|c|c|c|c|}
\hline & full period & pre-crash & post-crash \\
\hline Gas1Y & $0.4117 * *$ & $0.5301 * *$ & $0.3156 * *$ \\
\hline $\mathrm{p}$ & $(<0.001)$ & $(<0.001)$ & $(<0.001)$ \\
\hline Coal & 0.0238 & 0.0520 & 0.0125 \\
\hline $\mathrm{p}$ & $(0.371)$ & $(0.261)$ & $(0.504)$ \\
\hline Temp w & -4.0883 & -4.4527 & -4.4215 \\
\hline $\mathrm{p}$ & $(0.487)$ & $(0.829)$ & $(0.080)$ \\
\hline Temp S & 8.6996 & 18.6700 & 2.9514 \\
\hline$p$ & $(0.367)$ & $(0.474)$ & $(0.573)$ \\
\hline Prec & -0.6414 & -1.9232 & $-1.0388 *$ \\
\hline$p$ & $(0.410)$ & $(0.494)$ & $(0.034)$ \\
\hline Nordlev & 1.3395 & 17.8560 & 1.3654 \\
\hline$p$ & $(0.925)$ & $(0.707)$ & $(0.835)$ \\
\hline Crash & $-4.1734 * *$ & & \\
\hline$p$ & $(<0.001)$ & & \\
\hline L.ARCH & $0.8911 * *$ & $0.4908 * *$ & $2.2889 * *$ \\
\hline $\mathrm{p}$ & $(<0.001)$ & $(<0.001)$ & $(<0.001)$ \\
\hline $\mathrm{N}$ & 563 & 298 & 261 \\
\hline $\mathrm{AlC}$ & 798.47 & 473.51 & 259.74 \\
\hline $\mathrm{BIC}$ & 837.47 & 503.09 & 288.26 \\
\hline $\mathrm{Rsq}^{\mathrm{a}}$ & 0.1522 & 0.0574 & 0.1696 \\
\hline LR test (struct. break) & 21.8600 & & \\
\hline $\mathrm{p}$ & $(<0.001)$ & & \\
\hline $\mathrm{Q}(\mathrm{k})^{\mathrm{b}}$ & 74.82 & 49.86 & 44.48 \\
\hline $\mathrm{p}$ & $(0.006)$ & $(0.039)$ & $(0.070)$ \\
\hline
\end{tabular}


Table 3: Results from estimating extensions 1-3; dependent variable: Daily EUA price changes

\begin{tabular}{|c|c|c|c|c|c|c|c|c|c|c|c|c|}
\hline \multirow{3}{*}{$\begin{array}{l}\text { Dep. variable: } \\
\text { D.EUA }\end{array}$} & \multicolumn{4}{|c|}{ Extension 1} & \multicolumn{4}{|c|}{ Extension 2} & \multicolumn{4}{|c|}{ Extension 3} \\
\hline & \multicolumn{2}{|c|}{ Pre-crash } & \multicolumn{2}{|c|}{ Post-crash } & \multicolumn{2}{|c|}{ Pre-crash } & \multicolumn{2}{|c|}{ Post-crash } & \multicolumn{2}{|c|}{ Pre-crash } & \multicolumn{2}{|c|}{ Post-crash } \\
\hline & Coeff & ( $p$-value) & Coeff & ( $p$-value) & Coeff & ( $p$-value) & Coeff & ( $p$-value) & Coeff & ( $p$-value) & Coeff & (p-value) \\
\hline L.D.EUA & & & & & & & & & $0.1730 * *$ & $(0.009)$ & $0.0892 * *$ & $(<0.001)$ \\
\hline L2.D.EUA & & & & & & & & & -0.0636 & $(0.174)$ & & \\
\hline L3.D.EUA & & & & & & & & & $-0.1375^{* *}$ & $(<0.001)$ & & \\
\hline D.Gas1Y & 0.9118 & $(0.766)$ & -0.1416 & $(0.598)$ & 0.7826 & $(0.749)$ & 0.2757 & $(0.261)$ & -0.6813 & $(0.768)$ & 0.1166 & $(0.610)$ \\
\hline L.D.Gas1Y & & & & & $-0.2557 * *$ & $(0.008)$ & $0.05879 *$ & $(0.042)$ & -0.1469 & $(0.092)$ & $0.0673^{*}$ & $(0.016)$ \\
\hline L2.D.Gas1Y & & & & & -0.09007 & $(0.363)$ & -0.04392 & $(0.068)$ & 0.0946 & $(0.281)$ & $-0.0576 * *$ & $(0.001)$ \\
\hline D.Gas1M & & & & & $0.06160 * *$ & $(<0.001)$ & $0.02638 * *$ & $(0.0$ & $0.0812 * *$ & 1) & $0.0360 * *$ & $(<0$ \\
\hline L.D.Gas1M & & & & & $0.03189 * *$ & $(0.001)$ & $-0.03058 *$ & $(0.0$ & $0.0256 *$ & 7) & $-0.0377 * *$ & 01) \\
\hline L2.D.Gas1M & & & & & 0.00656 & $(0.709)$ & 0.003766 & $(0.758)$ & 0.0169 & $(0.205)$ & 0.0037 & $(0.743)$ \\
\hline D.GasS & & & & & & & $-0.03237 * *$ & $(<0.001)$ & & & $-0.0223 * *$ & $(<0.001)$ \\
\hline L.D.GasS & & & & & & & 0.0037 & $(0.559)$ & & & 0.0074 & 50) \\
\hline L2.D.GasS & & & & & & & $0.02333 * *$ & $(<0.001)$ & & & $0.0274 * *$ & $(<0.001)$ \\
\hline D.Coal & 0.4465 & $(0.474)$ & -0.0549 & $(0.806)$ & 0.6587 & $(0.215)$ & $-0.4829 *$ & $(0.013)$ & 0.6154 & $(0.180)$ & -0.3475 & 24) \\
\hline L.D.Coal & & & & & -0.04671 & & $0.03694 * *$ & & & & & \\
\hline L2.D.Coal & & & & & 0.05813 & $(0.2$ & $0.03999 * *$ & 1) & -0.0274 & & 0.0. & \\
\hline Ten & 2053.0 & $(0.229)$ & -80.352 & $(0.501)$ & 582.69 & $(0.6$ & -52.791 & & -1508.1 & & 46 & \\
\hline & -1186.2 & $(0)$. & $1690.9 * *$ & & -78 & & 163 & & & & & \\
\hline Pre & 5.8174 & $(0.8$ & $46 *$ & & 11.966 & $(0$. & $-32.87 \varepsilon$ & 1) & & & -35. & \\
\hline dlev & $-1985.6 *$ & 10.0 & -0.0627 & & $-2426.9 * *$ & & 3.09 & & -213 & $1<0$ & & \\
\hline$Y^{\wedge} 2 * 10^{-6}$ & -13.281 & (0.8 & $31.376^{* *}$ & $(<0$. & -4.3317 & & 6.8126 & & 21.432 & & 17.803 & 57) \\
\hline $2 * 10^{-6}$ & -1.1670 & $(0.883)$ & 0.7066 & $(0.858)$ & -3.1531 & 10. & $9.1898^{*}$ & & -3.6093 & & 7.2773 & 74) \\
\hline $1 \wedge 2$ & -3.6086 & $(0.238)$ & 0.1388 & $(0.5$ & -0.9074 & (0. & 0.08912 & 10. & 2.7722 & 27) & 0.2556 & 84) \\
\hline$\wedge 2$ & 2.1531 & $(0.306)$ & $-2.8844 * *$ & $(0.0$ & 1.4725 & $(0$. & $-2.7848 * *$ & 0. & 0.7327 & & -1.1700 & 04) \\
\hline Prec & -0.0252 & $(0.8$ & 0.0163 & $(0.2$ & 0.01039 & $(0$. & $0.04175 * *$ & $(<0$ & -0 . & & 0.07 & 01) \\
\hline Nordle & $2.5134 *$ & $(0.016)$ & 0.1059 & $(0.452)$ & $3.1082 * *$ & $(0.001)$ & $0.3345^{* *}$ & $(0.0$ & $2.7242 * *$ & $1<0$. & $0.4507 * *$ & 01) \\
\hline Y*TempW & -0.1740 & $(0.924)$ & -0.0706 & $(0.737)$ & -1.1843 & $(0.489)$ & -0.2838 & $(0.096)$ & 0.0720 & $(0.959)$ & -0.2638 & $(0.078)$ \\
\hline D.Gas] & 1.9609 & $(0.294)$ & 0.1494 & $(0.499)$ & 1.2579 & $(0.511)$ & 0.325 & $(0.228)$ & 2.0041 & $(0.205)$ & 0.0301 & $(0.916)$ \\
\hline D.Gas1Y*Prec & -0.3496 & $(0.670)$ & $-0.4944 * *$ & $(<0.001)$ & -0.6327 & $(0.353)$ & $-0.3057 * *$ & $(<0.001)$ & $-1.1454 *$ & $(0.034)$ & $-0.3896 * *$ & $(<0.001)$ \\
\hline D.Gas1Y* Nordlev & -8.1324 & $(0.511)$ & $-3.2232 * *$ & $(0.002)$ & -12.749 & $(0.222)$ & $-2.4166 *$ & $(0.043)$ & -11.174 & $(0.199)$ & $-3.7326 * *$ & $(<0.001)$ \\
\hline D.Coal*TempW & -0.6294 & $(0.526)$ & 0.0584 & $(0.594)$ & -0.9602 & $(0.245)$ & 0.16 & $(0.053)$ & -0.7725 & $(0.221)$ & 0.0781 & $(0.464)$ \\
\hline D.Coal*TempS & -1.1025 & $(0.476)$ & -0.1636 & $(0.115)$ & -1.1786 & $(0.298)$ & $-0.2494 * *$ & $(0.004)$ & -0.5487 & $(0.550)$ & $-0.3218 * *$ & $(0.004)$ \\
\hline D.Coal*Prec & 0.0417 & $(0.949)$ & -0.1278 & $(0.310)$ & -0.001281 & $(0.998)$ & $0.7407 * *$ & $(<0.001)$ & 0.4522 & $(0.28$ & $0.8385^{* *}$ & $(<0.001)$ \\
\hline D.Coal* Nordlev & $37.139 *$ & $(0.017)$ & 1.1904 & $(0.164)$ & $46.317^{* *}$ & $(<0.001)$ & $2.6239 *$ & $(0.021)$ & $40.688 * *$ & $(<0.001)$ & 0.5430 & $(0.581)$ \\
\hline L. ARCH & $0.7674^{* *} *$ & $(<0.001)$ & $3.3200 * *$ & $(<0.001)$ & $1.1649 * *$ & $(<0.001)$ & $2.9419 * *$ & $(<0.001)$ & $1.2742 * *$ & $(<0.001)$ & $2.8012 * *$ & $(<0.001)$ \\
\hline $\mathrm{N}$ & & & & & $2 \varepsilon$ & & 24 & & & & & \\
\hline AIC & & 10 & 169 & & 456 & 45 & 124. & & 403 & & 117 & \\
\hline $\mathrm{BIC}$ & & .83 & 254 & 61 & 569 & 68 & 243. & 27 & & & 239 & 68 \\
\hline $\mathrm{Rsq}^{\mathrm{a}}$ & & 198 & 0.4 & 10 & 0.2 & 71 & 0.59 & 79 & 0.3 & 80 & 0.6 & 12 \\
\hline LR vs. prev. spec. & 20.41 & $(0.202)$ & 122.68 & $(<0.001)$ & 29.08 & $(<0.001)$ & 72.27 & $(<0.001)$ & 56.27 & $(<0.001)$ & 11.71 & $(<0.001)$ \\
\hline $\mathrm{Q}(\mathrm{k})^{\mathrm{b}}$ & 57.85 & $(0.007)$ & 28.11 & $(0.664)$ & 45.12 & $(0.078)$ & 32.16 & $(0.409)$ & 37.11 & $(0.285)$ & 37.12 & $(0.208)$ \\
\hline
\end{tabular}

$*: \mathrm{p}<0.05 ; * *: \mathrm{p}<0.01 ; \mathrm{a}: \mathrm{Rsq}=1-[\mathrm{L}(0) / \mathrm{L}(\mathrm{b})]^{\wedge}(2 / \mathrm{N}) ; \mathrm{b}:$ Ljung-Box Q statistic with $\mathrm{k}=$ floor[ $\left[2^{*} \operatorname{sqrt}(\mathrm{N})\right]$ 


\section{Notes}

${ }^{1}$ The activity codes are defined as follows: 1: Combustion installations with a rated thermal input exceeding $20 \mathrm{MW}$; 2: Mineral oil refineries; 3: Coke ovens; 4: Metal ore (including sulfide ore) roasting or sintering installations; 5: Production of pig iron or steel (primary or secondary fusion) including continuous casting; 6: Production of cement clinker in rotary kilns or lime in rotary kilns or in other furnaces; 7: Manufacture of glass including glass fibre; 8: Manufacture of ceramic products by firing, in particular roofing tiles, bricks, refractory bricks, tiles, stoneware or porcelain; 9: Industrial plants for the production of (a) pulp from timber or other fibrous materials (b) paper and board; 10: Installations from other industries that opted into the system.

${ }^{2}$ Defined by activity code 1 . Besides power \& heat producers that sell their output on the market ("main activity producers”) this activity code also includes installations involved in the production of on-site power and heat (“autoproducers”). In 2005, main activity producers accounted for $93 \%$ of emissions from this sector (IEA data).

${ }^{3}$ In a simulation-based analysis of the EU ETS, Reilly and Paltsev [12] calculated marketclearing marginal abatement costs to be $€$ 0.6-0.9 for their base scenario, with prices in even the most extreme scenarios below $€ 7$. Medium price estimates by brokers were somewhat higher, of around $€ 5.00$ for the first phase [11].

${ }^{4}$ Emissions verification numbers were planned to be announced in May, but in late April reports were leaked that Belgium, France, the Czech Republic, the Netherlands and Estonia all had allowance surpluses, and the allowance shortage in Spain was much smaller than anticipated. By early May, the market was found to be $63.6 \mathrm{Mt}$ long, with 21 countries reporting. The announcement of the Polish surplus of another 26 Mt in September 2006 did not affect prices much. 
${ }^{5}$ The explanation given for including oil prices is not clear. They cite a study by Christiansen et al. [23] which looked at general determinants for greenhouse gas markets but is not specific to fuel switching in the EU's power sector. Little power is generated using oil in Europe, so a switch from oil to gas is not likely to be the marginal abatement activity.

${ }^{6}$ The dispatch order is the sequence by which generators are brought online and is usually based on least cost.

${ }^{7}$ For lignite, the situation would be different, since this type of coal is typically mined right next to the power plant (i.e. the power plant is built right next to the mine). However, I assume that lignite plants are not involved in production shifts for abatement purposes, because their operating costs are low.

${ }^{8}$ Data from International Energy Agency (IEA), energy statistics for OECD and non-OECD countries, 2008.

${ }^{9}$ Abatement consists of shifting production from the least efficient running coal generator to the most efficient gas generator that has free capacity. The more production is shifted from coal and gas, the greater will be the efficiency of the marginal coal generator and the lower the efficiency of the first extramarginal gas generator, such that the amount of abatement per unit of production shift decreases while at the same time the cost of the shift increases.

10 The derivation contained in an Appendix that is available at JEEM's online archive of supplementary material, which ban accessed at http://www.econ.iastate.edu/jeem/supplement.htm.

${ }^{11}$ This means that in theory, fluctuations in the allowance price should increase towards the end of the market. In practice, there is also an opposite effect: New markets typically show more 
volatility than mature ones because market participants learn. The ARCH term (see below) allows a changing variance in either direction.

${ }^{12}$ The choice of discount rate is more important for the right hand side because small changes can cause significant differences in the numerical value for the summation term. However, using discount rates of $5 \%$ and $20 \%$ did not significantly change the results.

${ }^{13}$ Installed hydroelectric capacity in the Nordic market (Norway, Sweden, Denmark and Finland) is $48 \mathrm{GW}$, compared to $25 \mathrm{GW}$ in France, $21 \mathrm{GW}$ each in Italy and Spain and $12 \mathrm{MW}$ in Austria, to name the largest hydropower producers. Because no readily available data exist on aggregate European reservoir levels outside of the Nordic market, I include precipitation to complement Nordic reservoir levels.

${ }^{14}$ This dummy is added outside the model in order to prevent the price adjustment caused by the first round of emissions verifications to contaminate the impact of the continuous fundamental variables. Although in theory such a price jump should not have happened because the allowance price supposedly incorporates all information about aggregate emissions and abatement, it seems clear that the price adjustment was not driven by any fundamentals related to abatement.

${ }^{15}$ The derivation of the econometric specification is eq. (A8) contained in the online Appendix (see note 10).

${ }^{16}$ AIC: Akaike Information Criterion; AIC=2k-2*ln(L); BIC=Bayesian Information Criterion; $\mathrm{BIC}=\mathrm{k} * \ln (\mathrm{n})-2 * \ln (\mathrm{L})$. Both trade off model fit and parsimony, with BIC putting relatively more weight on the latter. The lower AIC and BIC, the better the model fit. I chose to use the sum of AIC and BIC because neither is superior to the other on theoretical grounds, but some models had almost identical BIC but different AIC values. 
${ }^{17}$ Unfortunately, there are not several useful measures for coal prices. The coal index for North-Western Europe seems by far the best available price information for hard coal.

${ }^{18}$ Per lag structure: Three specifications with one gas price type; six specifications with two gas price types (two specifications for each of the three possible pairings, with squares interaction terms computed with one included gas price type); and three specifications with all three gas price types. I do this for zero, one, and two price lags.

${ }^{19}$ Available at www.pointcarbon.com.

${ }^{20}$ Klein Tank et al., "Daily Dataset of $20^{\text {th }}$-century surface air temperature and precipitation series for the European Climate Assessment”, 2007, available at http://eca.knmi.nl.

${ }^{21}$ I also employed specifications with the German index DAX, but the results were qualitatively the same. Daily stock market indices appear not to be related to allowance prices.

${ }^{22}$ Full results of the regime-switching tests are available from the author upon request. 